\title{
Zagreb Radio Indices of Some Graphs with Diameter Two
}

\author{
A.T. Raj ${ }^{1}$, and J. V. Kureethara ${ }^{2^{*}}$ \\ ${ }^{1}$ Dept. Mathematics, St. Teresa's College, Ernakulam, Kerala, India \\ $2^{2 *}$ Dept. Mathematics and Statistics, Christ University, Bengaluru, Karnataka, India \\ *Corresponding Author: frjoseph@christuniversity.in Tel.: +91-93410-94110
}

Available online at: www.isroset.org

Received: 21/Oct/2017, Revised: 05/Nov/2017, Accepted: 21/Nov/2017, Published: 31/Dec/2017

\begin{abstract}
A good amount of studies are there to explore the possibilities of non-laboratory characterization of molecules. In the field of quantitative structure-activity relationships (QSAR), topological indices play an important role. This paper is a perusal of the recently introduced topological indices called Zagreb radio indices. The Zagreb radio indices make use of the labeling of the vertices from the multi-level distance labeling of vertices called radio coloring. This is a vertex labeling with the condition on the distance between the vertices. Radio coloring is a non-negative integer labeling of the vertices of a graph such that difference of the colors of any pair of vertices is at least the difference between the diameter of the graph and the distance between those vertices plus one. This condition forces every vertex to have distinct labels. If the diameter of the graph is one, then radio coloring is nothing but the proper coloring. The Zagreb indices were originally introduced for the degrees of the vertices. Here, the Zagreb radio indices of some graphs of diameter two are computed replacing the degrees of the vertices with radio labels of the vertices originated from the minimal radio coloring.
\end{abstract}

Keywords-Zagreb Indices, Zagreb Radio Indices, Distance Labeling, Mathematical Chemistry, Diameter 2 graphs

\section{INTRODUCTION}

A graph $\mathrm{G}$ is a triple consisting of a vertex set $\mathrm{V}(\mathrm{G})$, an edge set $\mathrm{E}(\mathrm{G})$, and a relation that associates with each edge two vertices called endpoints.[1] Molecular graphs are graphs that are associated with molecules with elements as the vertices and their bonds as the edges. In the study of quantitative structure-activity relationships (QSARs) of molecules, some of the properties associated with the graph structure viz., the degree (valance) of vertices, the distances between the vertices (elements), the eccentricities of the vertices etc. have some observable correlation.

A topological index of a graph is a number calculated from the topological (structural) parameters of that graph. In 1971, Haruo Hosoya from the department of Chemistry of Ochanomizu University of Japan, recognized that boiling points of saturated hydrocarbons is correlated with an integer $Z$, which is the sum of a set of the numbers $\rho(G, k)$, the number of ways in which such $k$ bonds are so chosen from $G$ that no two of them are connected.[2] $\mathrm{He}$ named it topological index $\mathrm{Z}(\mathrm{G})$ of the graph $\mathrm{G}$. This was a big bang in the study of the quantitative structure-activity relationships (QSARs) of molecules and mere graph structures that need not represent molecules.

Numerous topological indices emerged in the last four decades. Interestingly, many of the topological indices are yet to be proved to have significance to some molecules. There are no exhaustive studies on all the topological indices. Nevertheless, readers may refer to [3] for a summary of the main properties of a large number of molecular-graph-based structure descriptors (topological indices) conceived depending on vertex degrees. It also provides a critical comparative study as well.

The organization of the paper is as follows. Section I contains the introduction and background of the topological indices. Related work is explained in Section II. Section III is about the methodology of the work. Section IV contains the computation of the first and the second Zagreb radio indices of path and cycles of diameter 2. One of the most famous graphs is the Petersen graph. In Section V, the first and the second Zagreb indices of the Petersen graph are computed as 285 and 258, respectively. In this section, the Zagreb radio indices of $\mathrm{C}_{4} \mathrm{xC}_{5}$ also are computed. The first and the second Zagreb radio indices of $\mathrm{C}_{4} \mathrm{xC}_{5}$ are 1015 and 1385, respectively. The Wheel graphs are another class of graphs with diameter 2. Section VI has the major result of this paper, which is the computation of Zagreb radio indices of wheel graphs of any order. Section VII concludes with the mention of research work in future directions.

\section{RELATED WORK AND METHODOLOGY}

In 1972, Gutman and Trinajstić coined two formulae analyzing the structure-dependency of the total $\pi$-electron 
energy of molecules.[4] They are $M_{1}(G)=\sum_{u \in V(G)} \operatorname{deg}(u)^{2}$ and $M_{2}(G)=\sum_{u v \in E(G)} \operatorname{deg}(u) \operatorname{deg}(v)$ where $\operatorname{deg}(u)$ stands for the degree of the vertex $u$ in the graph G. Balaban et al. named them Zagreb group indices. [5] Authors of this article introduced Zagreb radio indices.[6] They are analogous to the first and the second Zagreb indices of graphs where radio labels of vertices are replaced by the degrees of the vertices.

Radio labeling[7] is a labeling $c$ with non-negative integers, of the vertices of a graph $\mathrm{G}$ such that $|c(\mathrm{u})-c(\mathrm{v})| \geq 1+\operatorname{diam}(\mathrm{G})$ - $\mathrm{d}(u, v)$ where $\operatorname{diam}(\mathrm{G})$ is the diameter of the graph $\mathrm{G}$ and $\mathrm{d}(u, v)$ is the distance between the vertices $u$ and $v$. The first and second Zagreb radio indices are $M_{r c 1}(G)=$ $\sum_{u \in V(G)} c(u)^{2} \quad$ and $\quad M_{r c 2}(G)=\sum_{u v \in E(G)} c(u) c(v)$, respectively where $c$ is that radio labeling which gives the radio number of the graph $\mathrm{G}$. Radio number of a graph is the smallest among all the largest values of all possible radio labelings of the vertices of that graph.

\section{METHODOLOGY}

The major task in computing the Zagreb indices is to reduce the index value. Radio labeling assigns distinct labels to the vertices of a graph. Hence, the first Zagreb index does not require much of attention as it is nothing but the sum of the squares. However, in finding the second Zagreb index, care must be given to pairing of the labels to minimize the index. This is carefully done here.

\section{ZAGREB RADIO INDICES OF GRAPHS WITH DIAMETER AND MAXIMUM DEGREE 2}

It should include important findings discussed briefly. Wherever necessary, elaborate on the tables and figures without repeating their contents. Interpret the findings in view of the results obtained in this and in past studies on this topic. State the conclusions in a few sentences at the end of the paper. However, valid colored photographs can also be published.

It is not difficult to see that radio labelings of the vertices of a connected graph $\mathrm{G}$ assign distinct labels to the vertices. We now compute the Zagreb radio indices of connected graphs with diameter and maximum degree 2 . There are only three such graphs. They are $\mathrm{P}_{3}, \mathrm{C}_{4}$ and $\mathrm{C}_{5}$.

\section{A. Zagreb Radio Indices of Path $P_{3}$}

Radio labeling of $\mathrm{P}_{3}$ is given in Figure 1.

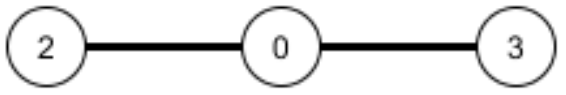

Figure 1
The first Zagreb radio index $M_{r c 1}\left(P_{3}\right) \quad=2^{2}+0^{2}+3^{2}=13$. The second Zagreb radio index

$$
M_{r c 2}\left(P_{3}\right)=2 \times 0+0 \times 3=0
$$

B. Zagreb Radio Indices of Path $C_{4}$

Radio labeling of $\mathrm{C}_{4}$ is given in Figure 2.

The first Zagreb radio index

$$
M_{r c 1}\left(C_{4}\right)=4^{2}+0^{2}+3^{2}+1^{2}=26
$$

The second Zagreb radio index

$$
M_{r c 2}\left(C_{4}\right)=3 \times 0+0 \times 4+4 \times 1+3 \times 1=7
$$

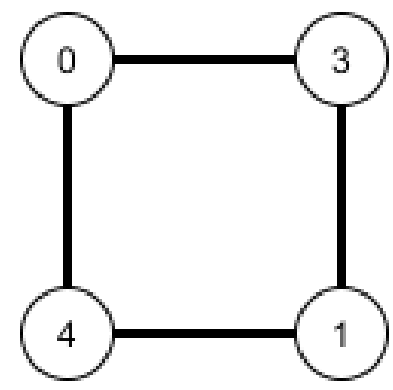

Figure 2

\section{Zagreb Radio Indices of Path $C_{5}$}

Radio labeling of $\mathrm{C}_{5}$ is given in Figure 3.

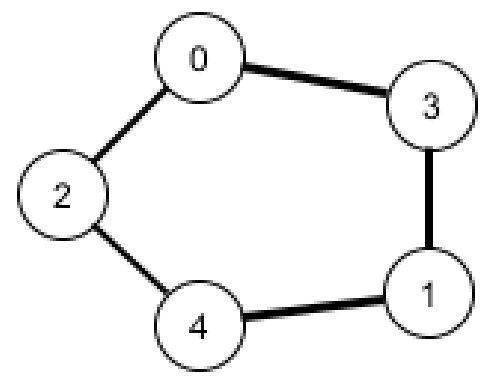

Figure 3

The first Zagreb radio index

$$
M_{r c 1}\left(C_{5}\right)=4^{2}+0^{2}+3^{2}+1^{2}+2^{2}=34 .
$$

The second Zagreb radio index

$$
M_{r c 2}\left(C_{5}\right)=3 \times 0+0 \times 2+4 \times 1+4 \times 2+3 \times 1=15
$$

\section{Zagreb RAdio Indices Of Petersen GraPH AND $\mathrm{C}_{3} \mathrm{XC}_{5}$}

The Petersen graph, $\mathrm{P}$, is a graph with diameter 2. Radio labeling of $\mathrm{P}$ is given in Figure 4. 


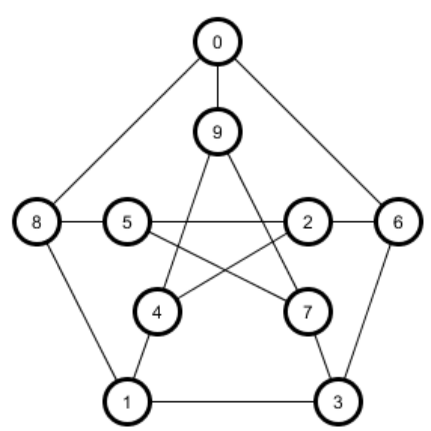

Figure 4

The first Zagreb radio index $M_{r c 1}(P)=0^{2}+1^{2}+\ldots+9^{2}=285$. The second Zagreb radio index $M_{r c 2}(P)=0(8+9+6)+9$ $(4+7)+8(5+1)+6(2+3)+2(4+5)+7(5+3)+1(4+3)=258$

Another graph of diameter 2 is $\mathrm{C}_{3} \mathrm{xC}_{5}$. Radio labeling of $\mathrm{C}_{3} \mathrm{xC}_{5}$ is given in Figure 5.[8]

The first Zagreb radio index $M_{r c 1}\left(C_{3} \times C_{5}\right)=$ $0^{2}+1^{2}+\ldots+14^{2}=1015$.

The second Zagreb radio index $M_{r c 2}\left(C_{3} \times C_{5}\right)=1385$

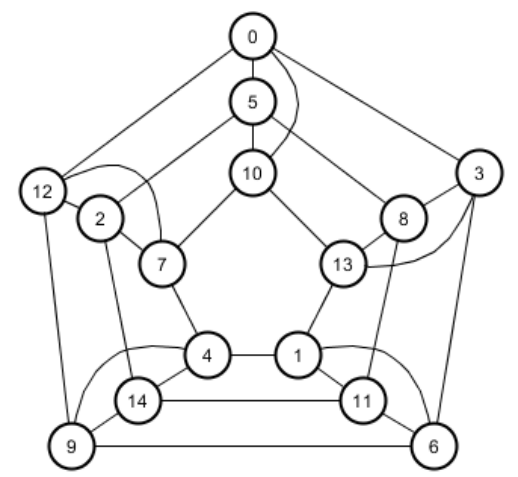

Figure 5

\section{ZAGREB RADIO INDICES OF WHEEL GRAPHS}

We now compute Zagreb radio indices of Wheel graph. The wheel is a graph of diameter 2. It has a central vertex with degree $|V(G)|-1$ and all other vertices with degree 3 . The smallest Wheel is $\mathrm{W}_{3}$. Its radio labeling is given in Figure 6.

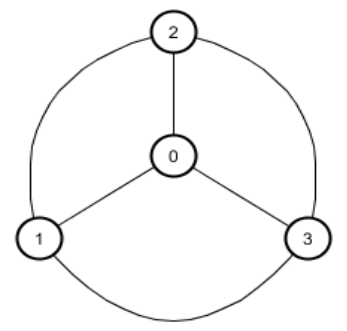

Figure 6
The first Zagreb radio index $M_{r c 1}\left(W_{3}\right)=0^{2}+1^{2}+2^{2}+3^{2}=14$ The second Zagreb radio index $M_{r c 2}\left(W_{3}\right)=1 \times 2+2 \times 3+1 \times 3=11$.

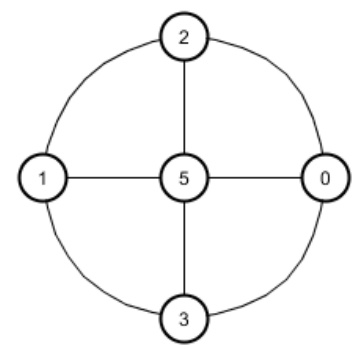

Figure 7

From $\mathrm{n} \geq 4$, the wheel graph is of diameter 2. Consider the $\mathrm{W}_{4}$. An optimal radio labeling is given in Figure 7.

The first Zagreb radio index $M_{r c 1}\left(W_{4}\right)=0^{2}+1^{2}+2^{2}+3^{2}+5^{2}=39$ The second Zagreb radio index

$$
M_{r c 2}\left(W_{4}\right)=5 \times 2+5 \times 3+1 \times 5+1 \times 2+1 \times 3=35
$$

The next wheel is $W_{5}$. The optimal radio labeling of $W_{5}$ is given in Figure 8.

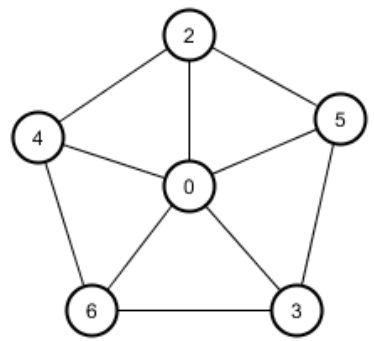

Figure 8

The first Zagreb radio index

$$
M_{r c 1}\left(W_{5}\right)=0^{2}+2^{2}+3^{2}+4^{2}+5^{2}+6^{2}=90
$$

The second Zagreb radio index

$$
M_{r c 2}\left(W_{5}\right)=5 \times 2+5 \times 3+6 \times 3+6 \times 4+4 \times 2=75
$$

We can continue in this manner and find the first and the second Zagreb indices of wheel graph until $n=11$. From $n \geq$ 12 , we compute the Zagreb radio indices of $\mathrm{W}_{\mathrm{n}}$ as in the following theorems.

Theorem 1. For a wheel graph $W_{n}$ with $n+1$ vertices, $M_{r c 1}\left(W_{n}\right)=\frac{(n+1)(n+2)(2 n+3)-6}{6}$.

Proof. We know that the radio number of the wheel, $\operatorname{rn}\left(\mathrm{W}_{\mathrm{n}}\right)$ $=n+1$.[9] Hence, for an optimal labeling, we use the labels 0 , $2,3, \ldots, n+1$. Hence, we have the result.

Theorem 2. For a wheel graph $\mathrm{W}_{\mathrm{n}}$ with $\mathrm{n}+1$ vertices, 


$$
\begin{gathered}
M_{r c 2}\left(W_{n}\right) \\
=\left\{\begin{array}{c}
\frac{4}{3} k^{3}+\frac{9}{2} k^{2}-\frac{5}{6} k+1 \text { when } n=2 k-1 \\
\frac{11}{12} k^{3}+15 k^{2}-\frac{337}{6} k+142 \text { when } n=2 k \text { and } k \geq 6 \text { and is even } \\
\frac{4}{3} k^{3}+\frac{25}{4} k^{2}+\frac{14}{3} k+\frac{7}{4} \text { when } n=2 k \text { and } k \geq 7 \text { and is odd }
\end{array}\right.
\end{gathered}
$$

Proof. The radio number of wheel, $r n\left(W_{n}\right)=n+1$.[9] Hence, we need to use all the integers of the set $\{0,2,3, \ldots, n+1\}$ in a radio labeling $c$ to get a span whose radio number is $n+1$. We develop a strategy to arrange these integers so that $\sum_{u v \in E(G)} c(u) c(v)$ is the minimum.

Since there are consecutive integers from 2 to $n+1$, to get the minimum sum, we pair up the larger integers with the smaller integers to get the product minimum. We consider the following cases.

\section{Case 1: $n=2 k-1$}

Let the central vertex of the wheel be $v_{0}$ and other vertices be $\mathrm{v}_{1}, \mathrm{v}_{2}, \ldots, \mathrm{v}_{\mathrm{n}}$ so that $\mathrm{v}_{1} \mathrm{v}_{2}, \mathrm{v}_{2} \mathrm{v}_{3}, \ldots, \mathrm{v}_{\mathrm{n}} \mathrm{v}_{1}$ are the vertices of the cycle. Let $c$ be the labeling of the vertices defined as $c\left(\mathrm{v}_{0}\right)=0$; $\mathrm{c}\left(\mathrm{v}_{2 \mathrm{i}-1}\right)=\mathrm{i}+1, \mathrm{i} \leq \mathrm{i} \leq \mathrm{k} ; c\left(\mathrm{v}_{2 \mathrm{i}+1}\right)=2 \mathrm{k}-\mathrm{i}, \mathrm{i} \leq \mathrm{i} \leq \mathrm{k}-4 ; c\left(\mathrm{v}_{2 \mathrm{k}-4}\right)=\mathrm{k}+2$ and $c\left(\mathrm{v}_{2 \mathrm{k}-2}\right)=\mathrm{k}+3$. In this labeling, not two adjacent vertices have consecutive integers. Hence, $c$ is a radio labeling.

Now, $\sum_{u v \in E(G)} c(u) c(v)=2.2 \mathrm{k}+2 \mathrm{k} .3+3(2 \mathrm{k}-1)+(2 \mathrm{k}-1) 4+\ldots$ $+(\mathrm{k}-2)(\mathrm{k}+4)+(\mathrm{k}+4)(\mathrm{k}-1)+(\mathrm{k}-1)(\mathrm{k}+2)$ $+(\mathrm{k}+2) \mathrm{k}+\mathrm{k}(\mathrm{k}+3)+(\mathrm{k}+3)(\mathrm{k}+1)+(\mathrm{k}+1) 2$

Let $\quad \mathrm{A}=2.2 \mathrm{k}+2 \mathrm{k} .3+3(2 \mathrm{k}-1)+(2 \mathrm{k}-1) 4+\ldots$ $+(\mathrm{k}-2)(\mathrm{k}+4)+(\mathrm{k}+4)(\mathrm{k}-1)$ and $\mathrm{B}=(\mathrm{k}-1)(\mathrm{k}+2)+(\mathrm{k}+2) \mathrm{k}+\mathrm{k}(\mathrm{k}+3)+(\mathrm{k}+3)(\mathrm{k}+1)+(\mathrm{k}+1) 2$.

Therefore, $\sum_{u v \in E(G)} c(u) c(v)=\mathrm{A}+\mathrm{B}$.

Now, $\quad A=2.2 \mathrm{k}+2 \mathrm{k} .3+3(2 \mathrm{k}-1)+(2 \mathrm{k}-1) 4+\ldots$ $+(\mathrm{k}-2)(\mathrm{k}+4)+(\mathrm{k}+4)(\mathrm{k}-1)$

$=(2 \mathrm{k}) 5+(2 \mathrm{k}-1) 7+\ldots+(\mathrm{k}+4)(2 \mathrm{k}-3)$

$=\sum_{i=0}^{k-4}(2 k-i)(2(i+2)+1)$

$=\sum_{i=0}^{k-4} 4 k i+10 k-2 i^{2}-5 i$

$=(4 k-5) \sum_{i=0}^{k-4} i-2 \sum_{i=0}^{k-4} i^{2}+\sum_{i=0}^{k-4} 1$

$=\frac{(4 k-5)(k-4)(k-3)}{2}-\frac{(k-4)(k-3)(2 k-7)}{3}+10 k(k-3)$

$=\frac{k^{2}}{2}+\frac{4}{3} k^{3}-\frac{77}{6} k-2$

$\mathrm{B}=4 \mathrm{k}^{2}+12 \mathrm{k}+3$

Hence, $\mathrm{A}+\mathrm{B}=\frac{4}{3} k^{3}+\frac{9}{2} k^{2}-\frac{5}{6} k+1$

Therefore,

$$
M_{r c 2}\left(W_{n}\right) \leq \frac{4}{3} k^{3}+\frac{9}{2} k^{2}-\frac{5}{6} k+1
$$

We prove that $M_{r c 2}\left(W_{n}\right)$ is indeed equal to $\frac{4}{3} k^{3}+\frac{9}{2} k^{2}-\frac{5}{6} k+1$.

If not, there is a labeling that gives a minimum sum than this. But to get the minimum sum, the lower values should be multiplied by the larger values. Therefore, let us swap the labels of $\mathrm{v}_{2 \mathrm{k}-4}$ and $\mathrm{v}_{2 \mathrm{k}-2}$.

Then $c\left(\mathrm{v}_{2 \mathrm{k}-1}\right)=\mathrm{k}+1$ and $c\left(\mathrm{v}_{2 \mathrm{k}-2}\right)=\mathrm{k}+2$. At once, we have a contradiction, since $\operatorname{diam}\left(\mathrm{W}_{\mathrm{n}}\right)$ is 2 , no two adjacent vertices can have the consecutive integers as labels.

Therefore,

$$
M_{r c 2}\left(W_{n}\right)=\frac{4}{3} k^{3}+\frac{9}{2} k^{2}-\frac{5}{6} k+1
$$

Case 2: $n=2 k$

We split this into two subcases depending on whether $\mathrm{k}$ is even or odd.

Subcase 1: $\mathrm{k}$ is even and $\mathrm{k} \geq 6$

Since the $n$-cycle is an even cycle, we label the vertices on the cycle as $\mathrm{v}_{1}, \mathrm{w}_{1}, \mathrm{v}_{2}, \mathrm{w}_{2}, \ldots, \mathrm{v}_{\mathrm{k}}, \mathrm{W}_{\mathrm{k}}$ so that $\left\{\mathrm{v}_{1} \mathrm{w}_{1}, \mathrm{w}_{1} \mathrm{v}_{2}, \mathrm{v}_{2} \mathrm{w}_{2}, \ldots\right.$, $\left.\mathrm{W}_{\mathrm{k}} \mathrm{V}_{1}\right\}$ is the edge set of the $\mathrm{n}$-cycle. Let $\mathrm{v}_{0}$ be the central vertex.

Let the labeling $c$ be defined as $c\left(\mathrm{v}_{0}\right)=0 ; c\left(\mathrm{v}_{\mathrm{i}}\right)=\mathrm{i}+1, \mathrm{i} \leq \mathrm{i} \leq \mathrm{k}$; $c\left(\mathrm{w}_{\mathrm{i}}\right)=2 \mathrm{k}+2-\mathrm{I}, 1 \leq \mathrm{i} \leq \mathrm{k} / 2 ; c\left(\mathrm{w}_{\mathrm{k}}\right)=(3 \mathrm{k} / 2)+1 ; \quad c\left(\mathrm{w}_{\mathrm{k}-1}\right)=\mathrm{k}+3 ; c\left(\mathrm{w}_{\mathrm{k}}-\right.$ $\left.{ }_{2}\right)=\mathrm{k}+2$ and $c\left(\mathrm{w}_{(\mathrm{k} / 2)+\mathrm{i}}\right)=(3 \mathrm{k} / 2)+1-\mathrm{i}, 1 \leq \mathrm{i} \leq(\mathrm{k} / 2)-3$.

It is not difficult to see that this is a radio labeling as none of the adjacent vertices on the n-cycle have consecutive integers as their labels.

Let $\sum_{u v \in E(G)} c(u) c(v)=\mathrm{A}+\mathrm{B}+\mathrm{C}$ where,

$$
\begin{aligned}
& \begin{aligned}
& \mathrm{A}=\left(\frac{3 k}{2}+1\right)(k+3)+(2 k+1)(k+3)+(2 k-1)(k+2) \\
&= \frac{11}{2} k^{2}+\frac{31}{2} k+4 \\
&=\sum_{i=1}^{\frac{k}{2}}[2(i+1)+1][2 k+2-i] \\
&=(4 k+4-3) \sum_{i=1}^{\frac{k}{2}} i-2 \sum_{i=1}^{\frac{k}{2}} i^{2}+(6 k+6) \sum_{i=1}^{\frac{k}{2}} 1 \\
&=\frac{5}{12} k^{3}+\frac{31}{8} k^{2}+\frac{37}{12} k \\
&=\sum_{i=0}^{\frac{k-8}{2}}[k+2(2+i)+1]\left[\frac{3 k}{2}-i\right] \\
& \mathrm{C} \quadk-5) \sum_{i=0}^{\frac{k-8}{2}} i+\left(\frac{3 k^{2}}{2}+\frac{15 k}{2}\right) \sum_{i=0}^{\frac{k-8}{2}} 1-2 \sum_{i=0}^{\frac{k-8}{2}} i^{2} \\
&=(3 k-=\frac{k^{3}}{2}+\frac{45 k^{2}}{8}-\frac{299 k+138}{4}
\end{aligned}
\end{aligned}
$$

Therefore, $\sum_{u v \in E(G)} c(u) c(v)=\mathrm{A}+\mathrm{B}+\mathrm{C}$

$$
=\frac{11 k^{2}}{12}+15 k^{2}-\frac{337 k}{6}+142
$$

Hence, $M_{r c 2}\left(W_{n}\right) \leq \frac{11 k^{3}}{12}+15 k^{2}-\frac{337 k}{6}+142$

We prove that $M_{r c 2}\left(W_{n}\right)=\frac{11 k^{3}}{12}+15 k^{2}-\frac{337 k}{6}+142$

If not, there will be an ordering of labels that gives a minimum sum. To get this minimum sum smaller integers have to be multiplied by larger integers.

Let us swap the labels of $\mathrm{w}_{\mathrm{k}-2}$ and $\mathrm{w}_{\mathrm{k}-1}$. 
But this will contradict the fact that no two adjacent vertices can have consecutive integers as labels.

Hence, we have, $M_{r c 2}\left(W_{n}\right)=\frac{11 k^{3}}{12}+15 k^{2}-\frac{337 k}{6}+142$.

Subcase 2: $\mathrm{n}=2 \mathrm{k}, \mathrm{k}$ is odd and $\mathrm{k} \geq 7$

Let the arrangement of vertices in the wheel be as described in Subcase 1.

Let $c$ be a labeling of the vertices such that $c\left(\mathrm{v}_{0}\right)=0$, $\mathrm{c}\left(\mathrm{v}_{\mathrm{i}}\right)=\mathrm{i}+1, \quad \mathrm{i} \leq \mathrm{i} \leq \mathrm{k} ; \quad \mathrm{c}\left(\mathrm{w}_{\mathrm{i}}\right)=2 \mathrm{k}+2-\mathrm{I}, \quad 1 \leq \mathrm{i} \leq(\mathrm{k}-1) / 2 \quad$ and $\mathrm{c}\left(\mathrm{w}_{\mathrm{k}}\right)=(3 \mathrm{k}+2) / 2 ; \quad \mathrm{c}\left(\mathrm{w}_{\mathrm{k}-1}\right)=\mathrm{k}+3 ; \quad \mathrm{c}\left(\mathrm{w}_{\mathrm{k}-2}\right)=\mathrm{k}+2 \quad$ and $\mathrm{c}\left(\mathrm{w}_{(\mathrm{k}+\mathrm{i}) / 2}\right)=(3 \mathrm{k}+2-\mathrm{i}) / 2,1 \leq \mathrm{i} \leq \mathrm{k}-6$.

This is obviously a radio labeling.

Then, $\sum_{u v \in E(G)} c(u) c(v)=\mathrm{A}+\mathrm{B}+\mathrm{C}+\mathrm{D}$ where

$$
\begin{aligned}
& \mathrm{A}=\sum_{i=1}^{\frac{k-1}{2}}(2(i+1)+1)(2 k+2-i) \\
& =(4 k+2-3) \sum_{i=1}^{\frac{k-1}{2}} i-2 \sum_{i=1}^{\frac{k-1}{2}} i^{2}+(6 k+6) \sum_{i=1}^{\frac{k-1}{2}} 1 \\
& =\frac{5 k^{3}}{12}+\frac{25 k^{2}}{8}-\frac{5 k}{12}-\frac{25}{8} \\
& \mathrm{~B}=\frac{(2 k+1)}{2}(k+4)-\frac{3 k^{2}+13 k+4}{2} \\
& \text { C } \quad=\sum_{i=1}^{\frac{k-1}{2}}(k+2(2+i))\left(\frac{3 k-2(i-1)-1}{2}\right) \\
& =(2 k-3) \sum_{i=1}^{\frac{k-1}{2}} i-2 \sum_{i=1}^{\frac{k-1}{2}} i^{2}+\left(\frac{3 k^{2}+13 k+4}{2}\right)\left(\frac{k-1}{2}\right) \\
& =\frac{11 k^{2}}{12}-\frac{31 k^{2}}{8}-\frac{209 k}{12}-\frac{21}{8} \\
& \mathrm{D}=(k+3)\left(\frac{3 k+3}{2}\right)+(2 k+1)(k+3)+(2 k-1)(k+2) \\
& =\frac{11 k^{2}}{2}+16 k+\frac{11}{2} \\
& =\frac{4}{3} k^{3}+\frac{25}{4} k^{2}+\frac{14}{3} k+\frac{7}{4} \\
& \text { Hence, } M_{r c 2}\left(W_{n}\right) \leq \frac{4}{3} k^{3}+\frac{25}{4} k^{2}+\frac{14}{3} k+\frac{7}{4}
\end{aligned}
$$

As done in the above cases, we see that if we alter these labeling either, we get a contradiction by assigning two adjacent vertices with consecutive integers as labels or the sum is larger.

Hence, we conclude that $M_{r c 2}\left(W_{n}\right)=\frac{4}{3} k^{3}+\frac{25}{4} k^{2}+\frac{14}{3} k+\frac{7}{4}$

\section{CONCLUSION}

In this paper, we have computed the first and second Zagreb radio indices of paths, cycles and wheel graphs with diameter 2. We also have computed the first and second Zagreb radio indices of Petersen graph and $\mathrm{C}_{3} \mathrm{xC}_{5}$. The first and the second Zagreb radio indices are introduced to help in the study of the quantitative structure-activity relationships (QSARs) of molecular graphs. Computing the measurable properties of molecules is a herculean task as it involves time, space and money. Hence, these types of studies that are mainly nonlaboratory works can help the scientists off-load their burden to a great extent. A real-time check of the Zagreb radio indices of molecular graphs can be a useful research activity in this direction.

\section{REFERENCES}

[1] D. B. West, "Introduction to Graph Theory", 2 ed., New Delhi: PHI Learning Private Ltd, 2012.

[2] H. Hosaya, "Topological Index. A Newly Proposed Quantity Characterizing the Topological Nature of Structural Isomers of Saturated Hydrocarbons," "Bulletin of the Chemical Society of Japan", vol. 44, no. 9, pp. 2332-2339, 1971.

[3] I. Gutman, "Degree-based topological indices," "Croatica Chemica Acta", vol. 86, no. 4, pp. 351-361, 2013.

[4] I. Gutman and N. Trinajstić, "Graph theory and molecular orbitals. Total $\varphi$-electron energy of alternant hydrocarbons," "Chemical Physics Letters", vol. 17, no. 4, pp. 535-538, 1972.

[5] A. T. Balaban, I. Motoc, D. Bonchev and O. Mekenyan, "Topological indices for structure-activity correlations," in "Steric Effects in Drug Design", Berlin, Springer-Verlag, pp. 21-55, 1983.

[6] A. T. Raj and J. V. Kureethara, "Zagreb Radio Indices of Graphs," unpublished, 2017.

[7] G. Chartrand, D. Erwin, F. Harary and P. Zhang, "Radio labelings of graphs," "Bulletin of the Institute of Combinatorics and its Applications", vol. 33, pp. 77-85, 2001.

[8] G. Chartrand and P. Zhang, "Colorings, Distance and Domination," in "Chromatic Graph Theory", Florida, CRC Press, p. 415, 2009.

[9] R. K. Yeh, "Labeling graphs with a condition at distance two", Columbia, SC: Department of Mathematics, University of South Carolina, 1990.

\section{AUTHORS PROFILE}

Anna Treesa Raj pursued BSc (Mathematics) from St. Teresa's College, Ernakulam affiliated to Mahatma Gandhi University, Kottayam and MSc (Mathematics) from Christ University, Bengaluru, India. She is currently working as an Assistant Professor in Department of Mathematics, St. Teresa's College (Autonomous), Ernakulam, Kerala. She has interests in the areas of Combinatorics and Fuzzy Mathematics.

Joseph Varghese Kureethara received his $\mathrm{PhD}$ in Mathematics from MS University, Tirunelveli, India in 2010. He has MSc Mathematics and MA Economics from Madras University. $\mathrm{He}$ is currently an Associate Professor in the Department of Mathematics, Christ University, Bangalore, India. $\mathrm{He}$ is the Mathematics issue editor of Mapana Journal of Sciences and reviewer of many Mathematics journals. He is the author forty-eight articles in the fields of Graph Theory, Number Theory, Church History, Sacred Liturgy and Sports both in English and Malayalam. He is an active blogger and his blog has a total of more than 110 thousand pageviews. He coedited two books. 